\title{
The effect of focal cerebral ischemia-reperfusion injury on TLR4 and NF-kB signaling pathway
}

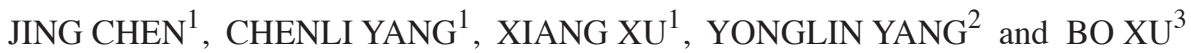 \\ ${ }^{1}$ No. 1 Department of Neurology, Qingdao Central Hospital, Shandong 266000; \\ ${ }^{2}$ Department of Neurosurgery, People's Hospital of Rizhao, Shandong 276800; \\ ${ }^{3}$ No. 2 Department of Neurology, Qingdao Central Hospital, Shandong 266000, P.R. China
}

Received July 7, 2017; Accepted October 24, 2017

DOI: $10.3892 / \mathrm{etm} .2017 .5463$

\begin{abstract}
The present study analyzed the change of Toll-like receptor 4 (TLR4) and nuclear factor $-\kappa B(N F-\kappa B)$ expression in focal cerebral ischemia-reperfusion injury model. A sample of 36 Sprague-Dawley rats were randomly selected and divided into sham operation group (group S), control group (group C) and Chrysanthemum ester group $(\mathrm{NF}-\kappa \mathrm{B}$ inhibitor, group $\mathrm{CE}$ ), each group consisted of 12 rats. The rat model of focal cerebral ischemia-reperfusion was established. The physiological indexes and neurological severity score of rats was recorded by a double-blind method. The cerebral infarction area was evaluated by triphenyltetrazole oxide (TTC) staining on brain slices. Apoptosis was evaluated by TUNEL staining. Semi-quantitative PCR and western blot analysis was used to measure the expression of TLR4 and NF- $\kappa \mathrm{B}$. The neurological severity score of rats in group $\mathrm{C}$ and $\mathrm{CE}$ were found to be significantly lower than group $\mathrm{S}(\mathrm{P}<0.01)$. The TTC staining results showed that group $\mathrm{C}$ and $\mathrm{CE}$ had different levels of cerebral infarction but the area of infarction in group $\mathrm{CE}$ was significantly lower than group $\mathrm{C}(\mathrm{P}<0.01)$. In addition, the number of TUNEL positive cells in group CE was significantly lower than group $\mathrm{C}(\mathrm{P}<0.01)$. Semi-quantitative PCR and westernblot analysis results showed that the expression of $\mathrm{NF}-\kappa \mathrm{B}$ and TLR4 of group $\mathrm{S}$ was significantly lower than that of group $\mathrm{C}$ and group $\mathrm{CE}(\mathrm{P}<0.01)$, the relative expression of $\mathrm{NF}-\kappa \mathrm{B}$ and TLR4 of group CE was significantly lower than that of group $\mathrm{C}(\mathrm{P}<0.01)$. Moreover, the expression of $\mathrm{NF}-\kappa \mathrm{B}$ p65/p50 of group $\mathrm{CE}$ and group $\mathrm{C}$ was significantly higher than that of group $\mathrm{S}(\mathrm{P}<0.01)$. This study concludes that the focal cerebral ischemia-reperfusion injury in rats can cause brain damage and cell apoptosis. This effect might be associated to the increased expression of NF- $\kappa \mathrm{B}$ and TLR4, and the activation of TLR4/NF- $\kappa \mathrm{B}$ signaling pathway.
\end{abstract}

Correspondence to: Dr Bo Xu, No. 2 Department of Neurology, Qingdao Central Hospital, 127 Siliunan Road, Qingdao, Shandong 266000, P.R. China

E-mail: xubodr@163.com

Key words: focal cerebral ischemia-reperfusion, Toll-like receptor 4 , nuclear factor- $\kappa \mathrm{B}$, rat

\section{Introduction}

Stroke is ranked in the second place among all the lethal diseases. It seriously affects the quality of life of patient and also brings huge economic pressure on the family and society (1-3). Clinically, stroke is divided into ischemic stroke and hemorrhagic stroke, where the ischemic stroke rate accountes for $\sim 80 \%$ of the incidences of stroke (4-6). The occurrence of ischemic stroke is due to the lack of cerebral blood supply and oxygen caused by various reasons, resulting in brain tissue necrosis. Reperfusion after cerebral ischemia sometimes does not only restore the normal brain function, but also aggravates tissue damage and dysfunction, which is called cerebral ischemia-reperfusion injury. Due to the compensation of human body, the damage caused by reperfusion only occurs on one side, that is, focal ischemiareperfusion injury (7-9). Evidence showed that inflammation is closely related to the death of neuronal cells and causes neurological deficits, in which nuclear transcription factor- $\kappa \mathrm{B}$ $(\mathrm{NF}-\kappa \mathrm{B})$ is one of the key genes that cause inflammation (10). Toll-like receptor (TLR) is a transmembrane receptor and its subtype which is extensively studied and has clear function is called TLR4. TLR is mainly involved in the identification of different pathogens related molecules and leads to increased secretion in inflammatory cells, which as a result cause systematic inflammatory response (11). It is not yet clear whether TLR4/NF- $\kappa \mathrm{B}$ signaling pathway is involved in focal cerebral ischemia-reperfusion injury. In this study, our aim is to explore the relationship between neurological damage caused by ischemia-reperfusion and TLR4 and NF- $\mathrm{B}$ signaling pathway in order to establish the focal cerebral ischemia-reperfusion injury model in rats and obtain the explicit mechanism of ischemia-reperfusion injury.

\section{Materials and methods}

Instruments and materials. The material used in this study

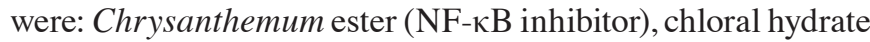
(both from Shanghai Aladdin Biochemical Technology Co., Ltd., Shanghai, China), triphenyltetrazole oxide (TTC; Sigma, St. Louis, MO, USA), ECL luminescent solution (Invitrogen, Carlsbad, CA, USA), DMSO (Sigma), RIPA lysate, protease inhibitor, phosphatase inhibitor (both from Servicebio, 
Wuhan, China). In addition kits and instruments used in this study were: TRIzol kit (Invitrogen), reverse transcription kit (Invitrogen), rabbit anti-rat NF- $\mathrm{B}$, rabbit anti-rat TLR4, rabbit anti-rat glyceraldehyde 3-phosphate dehydrogenase (GAPDH), rabbit anti-rat NF- $\mathrm{KB}$ p65/p50 polyclonal antibody (dilution, 1:1,000; cat. nos. 4764, 14358 and 13586; Cell Signaling Technology, Beverly, MA, USA), goat anti-rabbit IgG (heavy and lightchain) polyclonal antibody (dilution, 1:1,000; cat. no. 7074; Cell Signaling Technology, Beverly, MA, USA), terminal deoxynucleotidyltransferase-mediated dUTP nick end labelling (TUNEL) kit (Invitrogen), fluorescent inverted microscope (Thermo Fisher Scientific, Darmstadt Germany), pipette (Eppendorf, Hamburg, Germany), small animal anesthesia system (RWD Co., Ltd., Shenzhen, China), ultraviolet spectrophotometer (Beckman Coulter, Inc., Brea, CA, USA), electronic balance, low temperature centrifuge (both from Thermo Fisher Scientific). Other related equipments and reagents are described in the relevant part of this study.

Experimental animals. In this study, male SD rats, 8 weeks old, and weighing between 220-280 g, were obtained by the Animal Experimental Center of Jiangxi Province with the experimental animal certificate number: SCXK (Gan) 20150019. Before the experiment, all rats were adapted to the environment for 1 week and the diurnal rhythm was strictly followed during the adaptation period. The environment was kept quiet and the room temperature was $25^{\circ} \mathrm{C}$. The animals were allowed to drink and eat freely. The experiments on animal with the corresponding methods were approved by the Ethics Committee of Qingdao Central Hospital.

Experimental grouping and establishment of middle cerebral artery occlusion (MCAO) animal model. The $36 \mathrm{SD}$ rats were randomly divided into sham operation group (group S), blank control group (group C) and Chrysanthemum ester group (group CE). All rats were anesthetized by intraperitoneal injection of $4 \%$ chloral hydrate before operation and fixed on the mouse plate after anesthesia. After shaving the neck hair, the neck skin from the center of the rat neck was cut carefully, the muscle tissue were divided with tweezers to find the left common carotid artery. The rats in group $\mathrm{S}$ were also subjected to anesthesia and blood vessel separation whereas the rats in group CE were given $5 \mathrm{mg} / \mathrm{kg}$ of Chrysanthemum ester intraperitoneally $2 \mathrm{~h}$ before the operation. The left common carotid artery from rats in groupC and $\mathrm{CE}$ was isolated, and then the internal carotid artery and external carotid artery were isolated. The external carotid artery and common carotid artery was carefully ligated with suture. After clamping the distal end of carotid artery with the arterial clip, an incision was carefully opened with a syringe needle at the proximal end of the internal carotid artery and a thread with a diameter of $0.3 \mathrm{~mm}$ was inserted with the depth between $18.0 \pm 2.0 \mathrm{~mm}$ so that it could reach the beginning of the middle cerebral artery and completely block the arterial blood supply. At the same time, the internal carotid artery was ligated, and the thread was left outside $(\sim 1 \mathrm{~cm})$, and the skin was sutured. After the operation, the rats were placed on a warm blanket until they were awake. After $2 \mathrm{~h}$ of ischemia, the thread was gently pulled out and the rats were under reperfusion for $24 \mathrm{~h}$.
Detection of physiological indicators. During the operation, blood gas, blood pressure and body temperature of the animals was closely monitored by physiological signal recorder (Powerlab, Nuremberg, Germany). Supine position was taken for the rats during the surgery and left groin incision was also made. After separating the femoral artery, the pressure converters treated with heparin was inserted, blood pressure and arterial blood gas was monitored $20 \mathrm{~min}$ before placing the thread, 20 min after placing the thread and $20 \mathrm{~min}$ after removing the thread. In addition, the rectal temperature of the rats was monitored during the course of the experiment.

Neurological score. The neurological impairment score was obtained at 2, 8 and $24 \mathrm{~h}$ after cerebral ischemia-reperfusion, and the neurological behavior score was computed according to the Zea-Longa standard. In this standard, 0 point indicates no symptoms of neurological deficit that is normal activity, 1 point indicates that rat contralateral forepaws cannot stretch freely (mild neurological deficits), 2 points indicate circling to the contralateral side while walking (moderate neurological deficits), 3 points indicate body dumping to the contralateral side while walking (severe neurological deficits) and 4 points indicate loss of consciousness and unable to walk spontaneously. The neurological scores of all rats was counted and analyzed statistically.

TTC staining. After $24 \mathrm{~h}$ of taking reperfusion and after neurological scores, the rats were sacrificed. The brain was cut into $3 \mathrm{~mm}$ slices by the coronal plane, placed in $2 \%$ TTC solution, incubated in the incubator at $37^{\circ} \mathrm{C}$ for $5 \mathrm{~min}$ in the dark and then placed in $4 \%$ paraformaldehyde to get fixed. Survival tissue in the TTC solution was dyed bright red, necrotic tissue in the TTC solution was pale. After fixing for $24 \mathrm{~h}$, all the brain films were taken, the colorless parts were analyzed by using Image software and then the percentage of infarct volume was calculated.

Determination of brain cell apoptosis. Frozen slides of the brain tissue of each group were taken out from the $-80^{\circ} \mathrm{C}$ refrigerator, slightly dried and washed with phosphatebuffered saline (PBS) for $5 \mathrm{~min}, 1 \%$ Triton X-100 membrane for $15 \mathrm{~min}$, washed with PBS 3 times, $5 \mathrm{~min}$ each. Then incubated in $100 \mathrm{mM}$ glycine for $20 \mathrm{~min}$, washed with PBS 3 times, $5 \mathrm{~min}$ each. The experiment was in strict accordance with the TUNEL kit instructions: TUNEL reaction solution was prepared, the slide was added with TUNEL reaction solution and placed in a wet box, incubated in $37^{\circ} \mathrm{C}$ incubator in the dark for $1 \mathrm{~h}$, washed with PBS 3 times, 5 min each. Added with DAPI (DAPI:ultrapure water, 1:50) for $10 \mathrm{~min}$, washed with ultrapure water 3 times, 5 min each. The surrounding area of the tissue was aspired, one drop of anti-fluorescent quenching mounting medium was added for sealing, the slide was observed under fluorescence microscope and pictures were taken, preserved at $4^{\circ} \mathrm{C}$ in the dark, in which the cells with yellow-green fluorescence were positive, that is, apoptotic cells.

Gene and protein expression in TLR $4 / N F-\kappa B$ signaling pathway. Samples of the brain tissue of each group were 
Table I. PCR primers

\begin{tabular}{ll}
\hline Gene & \multicolumn{1}{c}{ Primer sequences } \\
\hline NF-кB & F: 5'-AACTGTTCCCCCTCATCTTC-3' \\
& R: 5'-TCCTACAAGCTCGTGGGGGT-3' \\
TLR4 & F: 5'-AGACATCCAAAGGAATACTGCAA-3' \\
& R: 5'-GCCTTCATGTCTATAGGTGATGC-3' \\
GAPDH & F: 5'-ATGGGGAAGGTGAAGGTCG-3' \\
& R: 5'-CCATCACGCCACAGTTTCC-3'
\end{tabular}

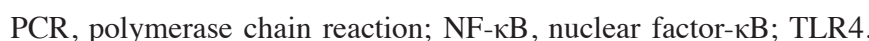
Toll-like receptor 4; GAPDH, glyceraldehyde 3-phosphate dehydrogenase; $\mathrm{F}$, forward; $\mathrm{R}$, reverse.

taken, ground in liquid nitrogen and transferred to a centrifuge tube containing $1 \mathrm{ml}$ of chloroform, vortexed for $10 \mathrm{sec}$ for the tissue samples to completely dissolve in chloroform, after 10 min ice bath, the sample was centrifuged at $4^{\circ} \mathrm{C}$ and $3,280 \mathrm{x}$ g for $20 \mathrm{~min}$, the supernatant was transferred to $1.5 \mathrm{ml}$ of RNase-free centrifuge tube, added with isopropyl alcohol of the same volume, centrifuged at $4^{\circ} \mathrm{C}$ and $3,280 \mathrm{xg}$ for $15 \mathrm{~min}$, added with $500 \mu \mathrm{l}$ of pre-cooled ethanol to wash the precipitation, then centrifuged at 3,280 x $\mathrm{g}$ for $15 \mathrm{~min}$, the supernatant was discarded and the sample was dried completely at room temperature, the precipitation was dissolved in $60 \mu \mathrm{l}$ of DEPC water and placed at $-80^{\circ} \mathrm{C}$. Two microliters of RT primer and $10 \mu \mathrm{l}$ of RNA and $1 \mu \mathrm{l}$ of dNTP mixture were mixed and placed at $65^{\circ} \mathrm{C}$ for $5 \mathrm{~min}$, and cDNA was obtained by reverse transcription strictly according to the reverse transcription kit. The expression of TLR4 and NF- $\kappa \mathrm{B}$ mRNA was detected by semi-quantitative PCR with GAPDH as the internal reference and using the cDNA as template. The PCR reaction conditions were as follows: $95^{\circ} \mathrm{C}$ predenaturation $5 \mathrm{~min}, 95^{\circ} \mathrm{C} 30 \mathrm{sec}, 64^{\circ} \mathrm{C} 25 \mathrm{sec}, 72^{\circ} \mathrm{C} 30 \mathrm{sec}$, a total of 35 cycles, extension at $72^{\circ} \mathrm{C}$ for $7 \mathrm{~min}$. Primers were synthesized by Shanghai Sangon Biotechnology Co., Ltd. The sequences are shown in Table I, and after the reaction, electrophoresis was performed using $2 \%$ agarose gel and the samples were observed by UV imaging. The low temperature was kept by placing the sample on ice, lysate was added at $1: 10$ ratio according to the weight of the brain tissue, the lysate contained $1 \%$ protease inhibitor and $1 \%$ of the phosphatase inhibitor, the tissue was homogenized using a homogenizer, 5 sec each time, until no visible tissue samples was observed, the EP tube was placed on ice during homogenizing, then the sample was centrifuged at $4^{\circ} \mathrm{C}, 3,280 \times \mathrm{g}$ for $10 \mathrm{~min}$, the supernant was obtained and the protein was quantitated using BCA protein quantitation kit. Twelve percent of the separated gel and $5 \%$ of the concentrated gel were prepared. After the gel was solidified, the same concentration of each protein sample was added to each well, electrophoresed at $80 \mathrm{~V}$ until the band reached the end of the glass plate, then transferred into a film using wet transfer method, transferring was conducted at $100 \mathrm{~V}$, for $90 \mathrm{~min}$. After transfer, the film was closed with $3 \%$ BSA-TBST for $1 \mathrm{~h}$, the target bands were cut, each monoclonal antibody was prepared according to 1:1,000 with 5\% BSA-TBST, using rabbit anti-GAPDH as internal
Table II. Physiological indexes of the rats.

\begin{tabular}{lcccc}
\hline $\begin{array}{l}\text { Physiological } \\
\text { indexes }\end{array}$ & $\mathrm{pH}$ & $\begin{array}{c}\mathrm{PaCO}_{2} \\
(\mathrm{mmHg})\end{array}$ & $\begin{array}{c}\mathrm{PaO}_{2} \\
(\mathrm{mmHg})\end{array}$ & $\begin{array}{c}\text { Rectal } \\
\text { temperature } \\
\left({ }^{\circ} \mathrm{C}\right)\end{array}$ \\
\hline Group S & $7.16 \pm 0.14$ & $43.5 \pm 1.9$ & $95.1 \pm 1.3$ & $36.5 \pm 0.2$ \\
Group C & $7.22 \pm 0.11$ & $43.1 \pm 1.3$ & $98.6 \pm 3.8$ & $36.2 \pm 0.1$ \\
Group CE & $6.72 \pm 0.15$ & $41.7 \pm 2.2$ & $95.1 \pm 2.6$ & $35.9 \pm 0.8$ \\
P-value & $>0.05$ & $>0.05$ & $>0.05$ & $>0.05$ \\
t-value & 1.036 & 0.892 & 0.573 & 1.328 \\
\hline
\end{tabular}

reference antibody, incubated overnight at $4^{\circ} \mathrm{C}$ with rabbit anti-TLR4, rabbit anti-NF- $\kappa \mathrm{B}$ and rabbit anti-NF- $\kappa \mathrm{B}$ p65/p50 antibody, washed three times with TBST and incubated for $2 \mathrm{~h}$ with the secondary antibody prepared at 1:5,000 ratio with 5\% skim milk, then washed with TBST again, adding ECL luminescent liquid (1:1 mix of A liquid and B liquid) in the dark, then the fixation time was determined according to the protein band fluorescence intensity, fixed after the development, then the bands were scanned and gray value analysis was performed using ImageJ software.

Statistical analysis. The data were processed and analyzed by SPSS 19.0 software (SPSS Inc., Chicago, IL, USA) and expressed as mean value \pm standard deviation. Moreover, t-test was used to compare the results between the groups. In addition, the analysis of variance (ANOVA) was used to compare the data among multiple groups. Homogeneity of variance was checked and if the variances were homogeneous, Bonferroni method was used for comparison. On the other hand, if the variances were not homogeneous, Welch method and multiple comparison using Dunnett's T3 method were employed. The level of significance was set at $\mathrm{P}<0.05$.

\section{Results}

Detection of physiological indexes. In order to rule out the effect of the operation method on the physiological indexes of rats, these indexes were monitored. The blood gas and body temperature of the SD rats in each group were tested during the pretreatment period and during the operation. The results showed (Table II) that there was no significant difference in the physiological indicators between the two groups $(\mathrm{P}>0.05)$.

Neurological function score. The neurological function scores were obtained in each group after focal ischemia-reperfusion and the results are presented in Fig. 1. The results showed that the neurological function scores of group $\mathrm{C}$ and $\mathrm{CE}$ were significantly higher than those of group $\mathrm{S}(\mathrm{P}<0.01)$. On the other hand, the score of neurological function for group $\mathrm{CE}$ was significantly lower than that of group $\mathrm{C}(\mathrm{P}<0.01)$.

TTC staining. The rat model of focal ischemia-reperfusion was established. The rats in group $\mathrm{C}$ and $\mathrm{CE}$ were stained with TTC after $2 \mathrm{~h}$ of ischemia and $24 \mathrm{~h}$ after reperfusion and at the same time, rats in group $\mathrm{S}$ were also sacrificed and the 


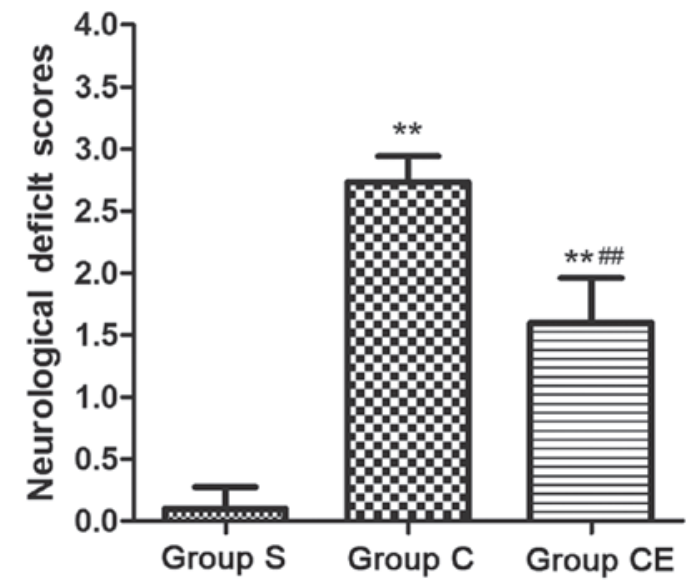

Figure 1. Neurological impairment was evaluated using neurological function score. The neurological function score in group $\mathrm{C}$ and $\mathrm{CE}$ were significantly higher than those in group $\mathrm{S}(\mathrm{P}<0.01)$, and the score in group $\mathrm{CE}$ was significantly lower than group $\mathrm{C}(\mathrm{P}<0.01) .{ }^{* *} \mathrm{P}<0.01$, compared with group $\mathrm{S}$; ${ }^{\# \#} \mathrm{P}<0.01$, compared wih group $\mathrm{C}$.

brain slice was stained with TTC. The results showed (Fig. 2) that the infarction area of group $\mathrm{S}$ was significantly smaller than that of group $\mathrm{C}$ and $\mathrm{CE}(\mathrm{P}<0.01)$, the infarction area of group $\mathrm{CE}$ was significantly smaller than that of group $\mathrm{C}$, the differences were statistically significant $(\mathrm{P}<0.01)$.

Brain cell apoptosis level. In order to establish rat model of focal ischemia-reperfusion, rats in group $\mathrm{C}$ and $\mathrm{CE}$ were stained with TUNEL after $2 \mathrm{~h}$ of ischemia and $24 \mathrm{~h}$ after reperfusion and at the same time, rats in group $\mathrm{S}$ were also sacrificed and the brain tissue was stained with TUNEL. Apoptosis is shown in Fig. 3. The TUNEL positive cells were barely not observed in the cortex of group $\mathrm{S}$, the number of TUNEL-positive cells in the cortex of the group $C$ and group $\mathrm{CE}$ was significantly higher than that of group $\mathrm{S}(\mathrm{P}<0.01)$, and the TUNEL-positive cells in group CE were significantly lower than in group $\mathrm{C}(\mathrm{P}<0.01)$.
Semi-quantitative PCR detection of $m R N A$ expression. The expression of NF- $\mathrm{KB}$ and TLR4 mRNA in the brain tissue of each group was detected by semi-quantitative PCR. The results showed that the expression levels of NF- $\mathrm{KB}$ and TLR4 in group $\mathrm{C}$ and $\mathrm{CE}$ were significantly higher than those in group $\mathrm{S}(\mathrm{P}<0.01)$. The expression of $\mathrm{NF}-\kappa \mathrm{B}$ and TLR4 in group $\mathrm{CE}$ was lower than that in group $\mathrm{C}(\mathrm{P}<0.01)$ (Fig. 4).

Protein expression detection with western blot analysis. The expression of NF-kB and TLR4 was detected by western blot analysis. The results are shown in Fig. 5. The expression of $\mathrm{NF}-\mathrm{KB}$ and TLR4 in groups $\mathrm{C}$ and $\mathrm{CE}$ were significantly higher than that of group $\mathrm{S}(\mathrm{P}<0.01)$. Moreover, the expression of NF- $\mathrm{KB}$ and TLR4 in group CE was lower than group $\mathrm{C}$ $(\mathrm{P}<0.01)$. In addition, the expression of $\mathrm{NF}-\mathrm{\kappa B} \mathrm{p} 65 / \mathrm{p} 50$ was detected (Fig. 6) and the expression of NF- $\mathrm{BB}$ p65/p50 in group $\mathrm{CE}$ and group $\mathrm{C}$ were significantly higher than group $\mathrm{S}$ $(\mathrm{P}<0.01)$.

\section{Discussion}

Stroke is one of the most serious diseases that affect human health. It is considered among the three major lethal diseases with cardiovascular disease and cancer (12). In Western developed countries, ischemic cerebrovascular disease accounts for $85 \%$ of total strokes. Ischemic stroke is due to the embolization or thrombosis of the brain vessels, mainly middle cerebral artery, which leads to brain blood supply interruption and then the emergence of energy metabolism disorders, ion steady-state imbalance, free radical production and excitatory neurotoxicity (13). TLR4 is widely distributed in the central nervous system. Studies have shown that TLR4 recognizes endogenous ligands released by ischemia-reperfusion injury, causing a series of inflammatory responses that seriously affect neurological function (14). The activation of NF- $\mathrm{kB}$ can lead to the expression of adhesion molecules and the corresponding receptors which play vital roles in the inflammatory response (15). The role of NF- $\mathrm{KB} / \mathrm{TLR} 4$ signaling pathway in
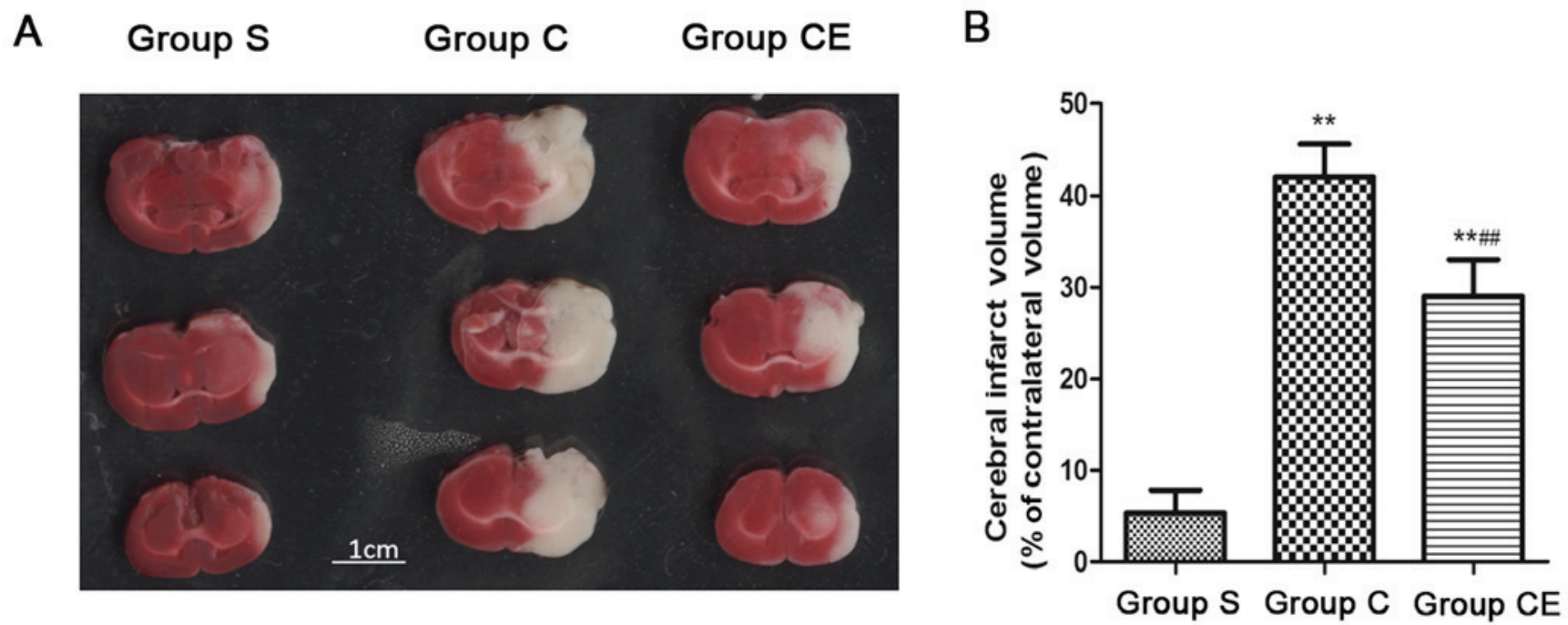

Figure 2. Triphenyltetrazole oxide (TTC) staining results of brain slices of each group. (A) TTC staining, scale bar, $1 \mathrm{~cm}$ and (B) cerebral infarction area chart, the infarction area of group $\mathrm{S}$ was significantly smaller than that of groups $\mathrm{C}$ and $\mathrm{CE}(\mathrm{P}<0.01)$, the infarction area of group $\mathrm{CE}$ was significantly smaller than that of group $\mathrm{C}(\mathrm{P}<0.01)$. ${ }^{* *} \mathrm{P}<0.01$, compared with group $\mathrm{S} ;{ }^{\# \#} \mathrm{P}<0.01$, compared wih group $\mathrm{C}$. 
A Group S
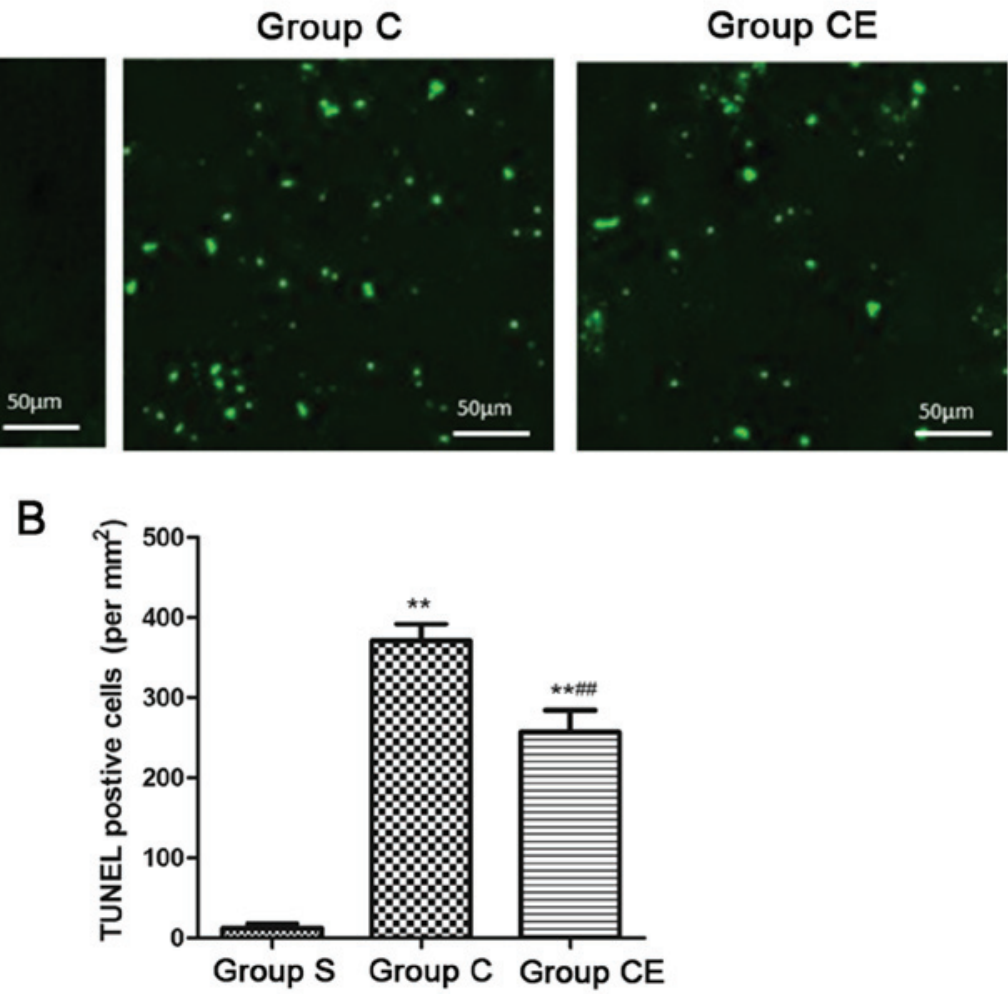

Figure 3. Terminal deoxynucleotidyltransferase-mediated dUTP nick end labelling (TUNEL) staining to detect TUNEL positive cells in the brain tissue of each group. (A) The staining under microscope bar, $50 \mu \mathrm{m}$ and (B) is for the statistical results. The number of TUNEL positive cells in the cortex of the group $\mathrm{C}$ and the group $\mathrm{CE}$ was significantly higher than that of group $\mathrm{S}(\mathrm{P}<0.01)$, and the TUNEL positive cells in group CE group were significantly lower than in group $\mathrm{C}(\mathrm{P}<0.01)$.

A

Group S Group C Group CE

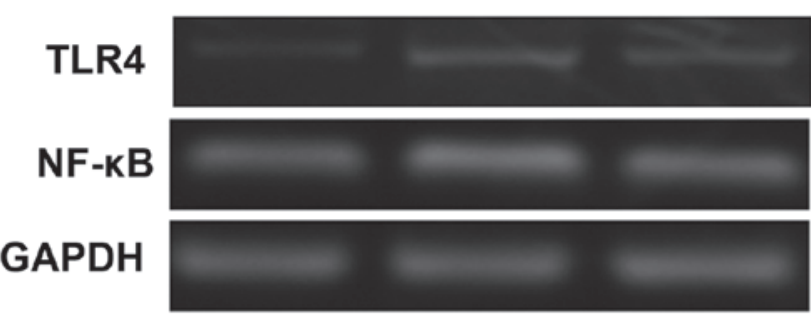

B

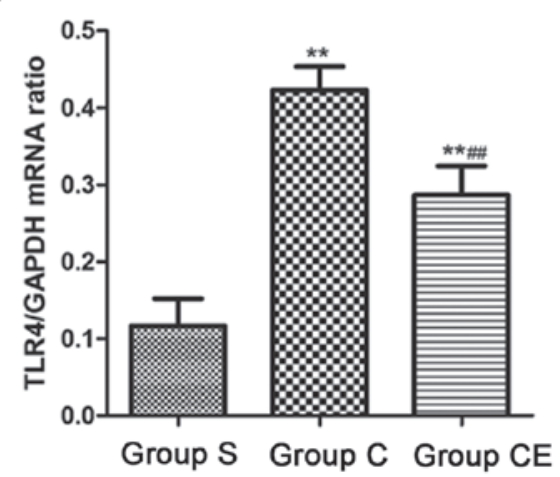

C

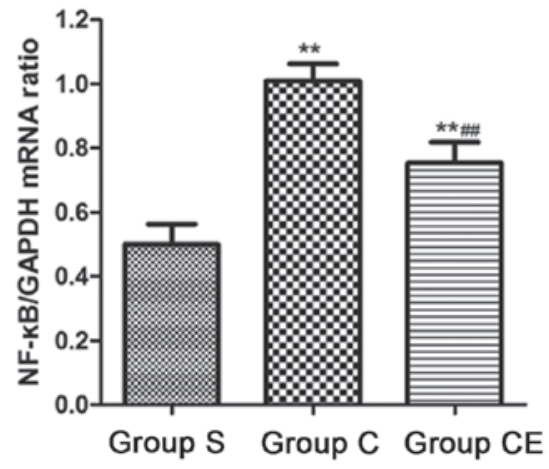

Figure 4. Semi-quantitative PCR detection of nuclear factor- $\kappa \mathrm{B}(\mathrm{NF}-\kappa \mathrm{B})$ and Toll-like receptor 4 (TLR4) mRNA expression. (A) The agarose gel electrophoresis image, $(\mathrm{B}$ and $\mathrm{C})$ the statistics. The expression levels of $\mathrm{NF}-\kappa \mathrm{B}$ and TLR4 in group $\mathrm{C}$ and $\mathrm{CE}$ were significantly higher than those in group $\mathrm{S}(\mathrm{P}<0.01)$. The expression of NF- $\mathrm{B}$ and TLR4 in group CE was lower than that in group $\mathrm{C}\left({ }^{\#} \mathrm{P}<0.01\right)$.

cerebral ischemia-reperfusion injury is gradually increasing and the regulation of NF-kB/TLR4 signaling pathway can reduce the damage caused by ischemia-reperfusion in brain tissue (16). 
A

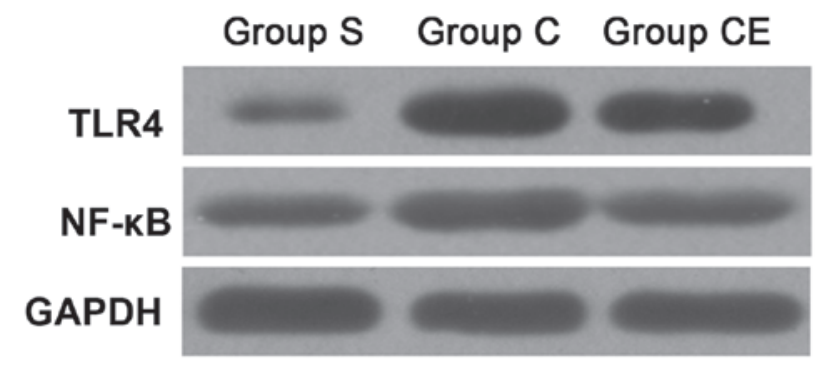

B

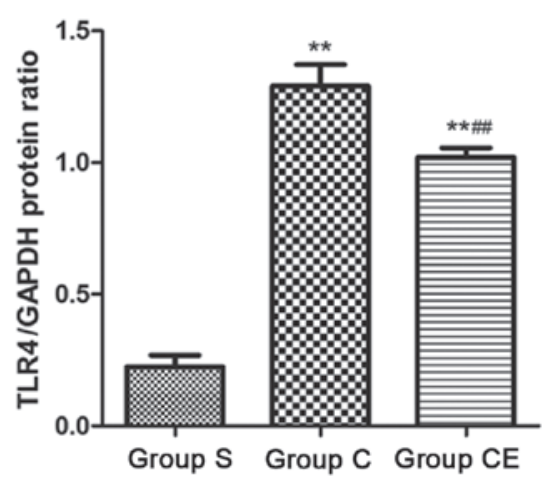

C

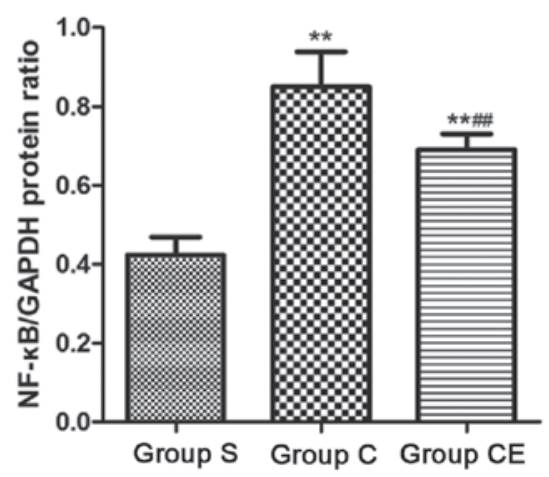

Figure 5. Western blot analysis detection of nuclear factor- $\kappa \mathrm{B}(\mathrm{NF}-\kappa \mathrm{B})$ and Toll-like receptor 4 (TLR4) protein expression. (A) The immune blot and (B and C) the statistics. Compared with group $\mathrm{S}$, the expression levels of $\mathrm{NF}-\kappa \mathrm{B}$ and TLR4 in group $\mathrm{C}$ and $\mathrm{CE}$ increased significantly $(\mathrm{P}<0.01)$. The expression of $\mathrm{NF}-\kappa \mathrm{B}$ and TLR4 in group CE was lower than that in group $\mathrm{C}(\mathrm{P}<0.05)$.

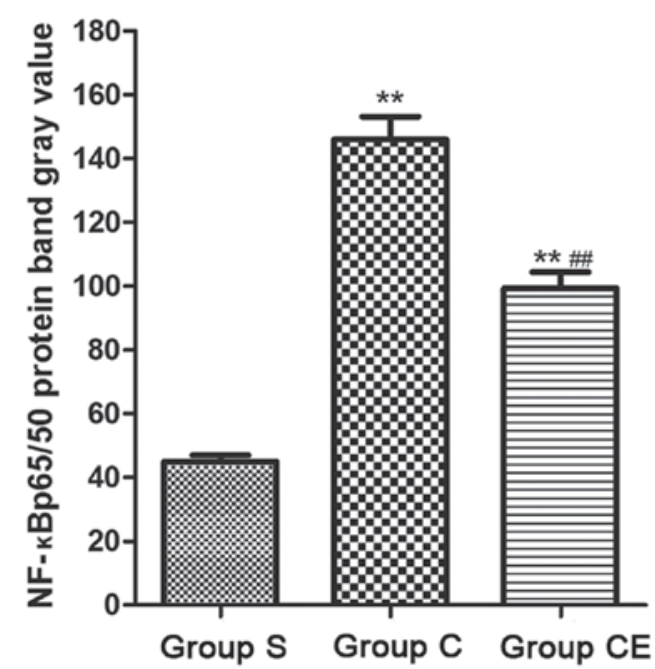

Figure 6. The expression of nuclear factor- $\kappa \mathrm{B}(\mathrm{NF}-\kappa \mathrm{B}) \mathrm{p} 65 / \mathrm{p} 50$ in brain tissue of rats detected by western blot analysis. In comparison to group $\mathrm{S}$, the expression was significantly increased in group $\mathrm{CE}$ and group $\mathrm{C}(\mathrm{P}<0.01)$, the expression in group $\mathrm{CE}$ was lower than group $\mathrm{C}(\mathrm{P}<0.01)$.

In this study, we investigated whether TLR4 and NF- $\mathrm{BB}$ are involved in the regulation of nerve injury by studying focal cerebral ischemia-reperfusion injury in rats. The inhibitor of $\mathrm{NF}-\kappa \mathrm{B}$ and Chrysanthemum ester was taken as a control. It was clarified whether NF- $\kappa \mathrm{B}$ is involved in the regulation of cerebral ischemia-reperfusion injury. Furthermore, the physiological indexes of rats were monitored during the operation, which showed that the MCAO model did not affect the physiological status of the rats. The MCAO animal model could simulate the ischemia-reperfusion injury of the human body, and it was highly consistent with the pathological changes of the human body with the advantage of a short operation time and causing little damage to the experimental animals (17). Studies have shown that $N F-\kappa B$ is involved in the regulation of brain injury because $\mathrm{NF}-\kappa \mathrm{B}$ activation is closely related to neurological impairment (18). The neurological function of rats was scored after the injury and the results showed that the scores of rats in group $\mathrm{C}$ were significantly increased. This means that ischemia-reperfusion could cause serious damage to the neurological function of rats. Moreover, the score in group $\mathrm{CE}$ was significantly lower than that of group $\mathrm{C}$ which indicates that inhibiting $\mathrm{NF}-\kappa \mathrm{B}$ has a protective effect on the rat's neurological function. In addition, TTC staining and TUNEL staining were used to evaluate the damage of brain tissue caused by ischemia-reperfusion from the morphological and apoptotic levels. The results showed that ischemia-reperfusion could significantly increase the cerebral infarct size and increase the level of apoptosis in brain tissue. However, Chrysanthemum ester can significantly reduce the level of cerebral infarction and apoptosis, and can fight against ischemia-reperfusion which in fact plays a protective role on the brain tissue of rats. The expression of $\mathrm{NF}-\kappa \mathrm{B}$ signaling pathway and TLR4 protein was studied by using semi-quantitative PCR and western blot analysis. The results show that the expression of $\mathrm{NF}-\kappa \mathrm{B}$ and TLR4 in group $\mathrm{C}$ were significantly higher than that in group $\mathrm{S}$, and NF- $\mathrm{NB}$ p65/p50 was significantly higher than that in group $\mathrm{S}$. This indicates that ischemia-reperfusion injury can increase the expression of $N F-\kappa B$ and TLR4, activating NF- $\kappa$ B signaling pathway which causes brain injury. The endogenous and exogenous substances in focal cerebral ischemia-reperfusion injury can increase the expression of $\mathrm{NF}-\kappa \mathrm{B}$, activating $\mathrm{NF}-\kappa \mathrm{B}$ signaling pathway. $\mathrm{NF}-\kappa \mathrm{B}$ is transformed from $\mathrm{p} 50$ homodimer to $\mathrm{p} 60$ heterodimer with transcriptional activity; activated $\mathrm{NF}-\kappa \mathrm{B}$ was transferred from the cytoplasm to the nucleus to play a transcriptional role, which produces a series of inflammatory 
factors, promotes the production of inflammatory response. Moreover, NF- $\mathrm{KB}$ p65/p50 was increased which indicates the activation of NF- $\mathrm{BB}$ signaling pathway, which can further lead to the release of a large number of inflammatory factors. These factors cause inflammation which leads to increased levels of apoptosis in brain tissue, and thus causing neurological function damage. Endogenous substances produced from brain damage can become TLR4 ligand, thereby increasing the inflammatory response $(19,20)$. Compared with group C the $\mathrm{CE}$ showed reduced levels of NF- $\kappa \mathrm{B}$ and $\mathrm{NF}-\kappa \mathrm{B}$ p $65 / \mathrm{p} 50$, which further demonstrate that NF- $\kappa \mathrm{B}$ plays a role in cerebral ischemia-reperfusion injury.

In conclusion, the model of cerebral ischemia-reperfusion injury in rats confirmed that ischemia-reperfusion injury could increase the expression of TLR 4 and $\mathrm{NF}-\kappa \mathrm{B}$, activate TLR4/NF- $\kappa \mathrm{B}$ signaling pathway, induce neuronal apoptosis and affect neuronal function. By inhibiting $\mathrm{NF}-\kappa \mathrm{B}$, reducing the expression of TLR4, inhibiting TLR4/NF- $\kappa \mathrm{B}$ signaling pathway can play a protective role on focal ischemia-reperfusion injury.

\section{Acknowledgements}

This study was supported by Qingdao Health Science and Technology Plan Project (no. 2016WJZD046).

\section{References}

1. Park JS, Hwang NK, Oh DH and Chang MY: Effect of head lift exercise on kinematic motion of the hyolaryngeal complex and aspiration in patients with dysphagic stroke. J Oral Rehabil 17: 554-559, 2016.

2. Keppel HJM: A novel selective AMPA antagonist for stroke, neuropathic pain or epilepsy? Drug Development Lessons Learned. Drug Dev Res 95: 126-132, 2016.

3. Seto SW, Chang D, Jenkins A, Bensoussan A and Kiat H: Angiogenesis in ischemic stroke and angiogenic effects of Chinese herbal medicine. J Clin Med 5: 630-645, 2016.

4. Vasileva D, Lubenova D, Mihova M, Grigorova-Petrova K and Dimitrova A: Orthostatic reactivity in patients with ischemic stroke in the chronic period. Open Access Maced J Med Sci 3 : 851-855, 2015.

5. Boisserand LS, Kodama T, Papassin J, Auzely R, Moisan A, Rome C and Detante O: Biomaterial applications in cell-based therapy in experimental stroke. Stem Cells Int 2016: 6810562 2016.

6. Liang Y, Huang J, Tian J, Cao Y, Zhang G, Wang C, Cao Y and Li J: The prevalence and risk factors of stroke in patients with chronic schizophrenia. Neuropsychiatr Dis Treat 12: 1131-1134, 2016.

7. Crivera C, Nelson WW, Schein JR and Witt EA: Attitudes toward anticoagulant treatment among nonvalvular atrial fibrillation patients at high risk of stroke and low risk of bleed. Patient Prefer Adherence 10: 795-805, 2016.
8. Wang Y and Bajorek B: Clinical pre-test of a computerised antithrombotic risk assessment tool for stroke prevention in atrial fibrillation patients: Giving consideration to NOACs. J Eval Clin Pract 22: 892-898, 2016.

9. Hastrup S, Damgaard D, Johnsen SP and Andersen G: Prehospital acute stroke severity scale to predict large artery occlusion: Design and comparison with other scales. Stroke 21: 487-491, 2016.

10. Zhang H, Li L, Sun Y, Zhang X, Zhang Y, Xu S, Zhao P and Liu T: Electroacupuncture could regulate the NF- $\mathrm{kB}$ signaling pathway to ameliorate theinflammatory injury in focal cerebral ischemia/reperfusion model rats. J Neurochem 137: 713-725, 2016.

11. Oshiro AH, Otsuki DA, Hamaji MW, Rosa KT, Ida KK, Fantoni DT and Auler JO Jr: Differential Roles of TLR 2 and TLR4 in acute focal cerebral ischemia/reperfusion injury in mice. Brain Res 70: 577-590, 2015

12. Gauberti M, Obiang P, Guedin P, Balossier A, Gakuba C, Diependaele AS, Chazalviel L, Vivien D, Young AR, Agin V, et al: Thrombotic stroke in the anesthetized monkey (Macaca mulatta): Characterization by MRI - a pilot study. Cerebrovasc Dis 33: 329-339, 2012.

13. Hinohara H, Kadoi Y, Takahashi K, Saito S, Kawauchi C and Mizutani A: Time course of changes in cerebral blood flow velocity after tourniquet deflation in patients with diabetes mellitus or previous stroke under sevoflurane anesthesia. J Anesth 25: 409-414, 2011.

14. Ying W, Pengfei G and Yuhong Z: TLR2 and TLR4 in the brain injury caused by cerebral ischemia and reperfusion. Mediators Inflamm 9: 2-9, 2016.

15. Lu L, Zhang G, Song C, Wang X, Qian W, Wang Z, Liu Y, Gong S and Zhou S: Protection of ischemic post conditioning against transient focal ischemia-induced brain damage is associated with inhibition of neuroinflammation via modulation of TLR2 and TLR4 pathways. J Neuroinflammation 16: 686-691, 2016.

16. Tomuschat C, O' Donnell AM, Coyle D, Dreher N, Kelly D and Puri P: Neuroprotective effect of kaempferol flycosides against brain injury and neuroinflammation by inhibiting the activation of NF-kB and STAT3 in transient focal stroke. Pediatr Res 80: 1787-1799, 2016.

17. Zhang M, Yin HJ, Wang WP, Li J and Wang XL: Over-expressed human TREK-1 inhibits CHO cell proliferation via inhibiting PKA and p38 MAPK pathways and subsequently inducing G1 arrest. Acta Pharmacol Sin 37: 1190-1198, 2016.

18. Levitz J, Royal P, Comoglio Y, Wdziekonski B, Schaub S, Clemens DM, Isacoff EY and Sandoz G: Long non-coding RNA C2dat1 regulates CaMKII $\delta$ expression to promote neuronal survival through the NF- $\mathrm{BB}$ signaling pathway following cerebral ischemia. Proc Natl Acad Sci USA 113: 266-271, 2016.

19. Zhu HT, Bian C, Yuan JC, Chu WH, Xiang X, Chen F, Wang CS, Feng $\mathrm{H}$ and Lin JK: Curcumin attenuates acute inflammatory injury by inhibiting the TLR4/MyD88/NF- $\mathrm{BB}$ signaling pathway in experimental traumatic brain injury. J Neuroinflammation 62 : 97-110, 2016.

20. Vivier D, Bennis K, Lesage F and Ducki S: Daphnetin protects against cerebral ischemia/reperfusion injury in mice via inhibition of TLR4/NF- $\kappa \mathrm{B}$ signaling pathway. Biomed Res 59: 328-335, 2016.

This work is licensed under a Creative Commons Attribution-NonCommercial-NoDerivatives 4.0 International (CC BY-NC-ND 4.0) License. 